\title{
Lima, ciudad renacentista
}

\author{
Enrique Bonilla Di Tolla \\ (Universidad de Lima, Perú)
}

Recibido: 6/4/2015

Aprobado: 5/6/2015

\begin{abstract}
RESUMEN. El presente artículo establece la pertinencia de llamar a Lima ciudad renacentista, tanto por la época en la que fue fundada, el siglo XVI, como por la coincidencia en su trazado con los modelos de orden que proponen los teóricos renacentistas de la arquitectura y, como se demostraría más tarde, coincide también con los trazados romanos, desconocidos hasta el siglo XVIII.
\end{abstract}

Palabras clave: Lima / ciudad / Renacimiento / ciudad renacentista

\section{Lima, a Renaissance City}

Summary. This article establishes the relevance of calling Lima a renaissance city. This, both due to the time in which it was founded, on the $16^{\text {th }}$ century, and to the accordance of its layout with models that arose from architectural theorists during the Renaissance, that as it would be shown later also coincide with Roman paths, unknown until the $18^{\text {th }}$ century.

Key words: Lima / city / renaissance / renaissance city 
Pizarro fundó Lima con estilo imperial, militar con mística de grandeza, de época, como se fundaron muchas ciudades florecientes en el mundo bajo muchos imperios. El oro no era exactamente en el siglo XVI el oro de los gangsters y usureros de hoy; tenía un sentido maravilloso de alquimia.

Héctor Velarde (1966).

\section{Introducción}

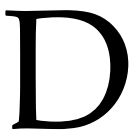

urante mucho tiempo se ha especulado sobre el origen de la trama urbana, una traza en forma de Damero, que caracteriza a las ciudades hispanoamericanas. Se le ha vinculado en principio a los castrum romanos que organizaron todo el territorio del imperio y manejaron en escala distinta la organización de la ciudad romana. Trazadas en torno a dos ejes, uno que seguía el movimiento del sol (decumanum) y el otro el aparente movimiento de la tierra (cardum), corresponden a nuestros actuales ejes este-oeste y norte-sur. Con este modelo, absolutamente pragmático, es que se trazaron las ciudades para dominar el vasto territorio imperial.

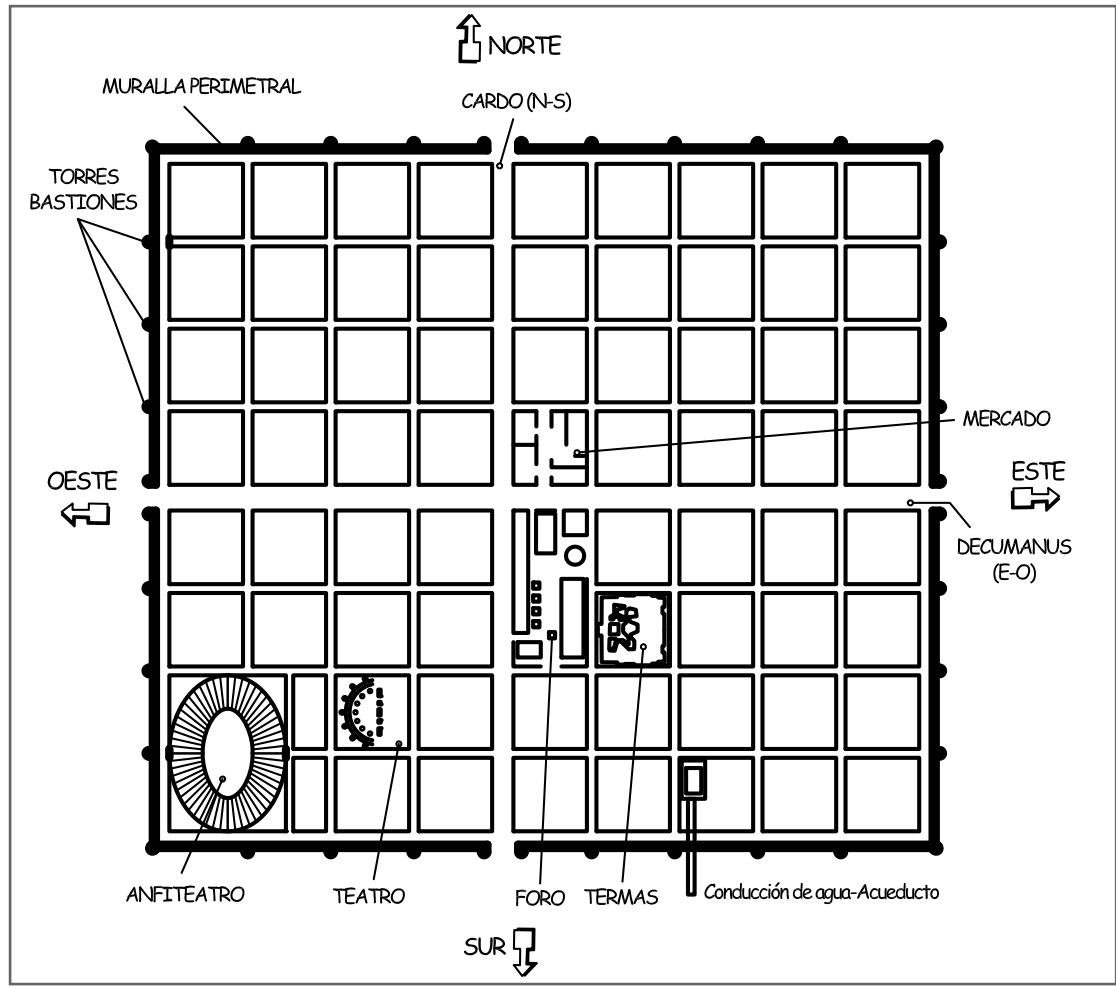

Traza de la ciudad romana.

Fuente: http://sdelbiombo.blogia.com/2009/112601-la-ciudad-romana-1-introduccion.php 
Sin embargo, atribuirle a la ciudad americana un vínculo con este urbanismo remoto me parece equivocado. La mayor parte de ciudades europeas se extinguieron durante la baja Edad Media y las pocas a las que no les sucedió esto se redujeron a su mínima expresión en este periodo. El repoblamiento y crecimiento de la ciudad de la alta Edad Media se hizo de una manera muy espontánea, utilizando parcialmente los trazados preexistentes, alterándolos con nuevos trazados y nuevos ejes, de manera que llegado el Renacimiento era muy difícil reconocer el trazado romano dentro de las ciudades. Prueba de ello es que los tratadistas, como Alberti, Filarete, Scamozzi, etc., infieran, a partir de la lectura de los textos de Vitruvio, una ciu- dad ordenada y centralizada, pero que difiere notablemente del trazado romano. Es más, no será hasta mediados del siglo XVIII, con el descubrimiento de las ruinas de Pompeya y Herculano, que Occidente tendrá una noción clara de lo que fue la ciudad romana, e inclusive cómo era la vivienda romana, cuestiones que eran absolutamente desconocidas para el más versado de los humanistas renacentistas.

Si observamos los planos de la ciudad de Florencia del siglo $\mathrm{XV}$, vemos cómo la ciudad cuna del Renacimiento tiene una estructura urbana de ciudad medieval, construida a la vera de los caminos o borgos, que la articulan con el territorio toscano y que se cruzan y forman el trazado de la propia ciudad.

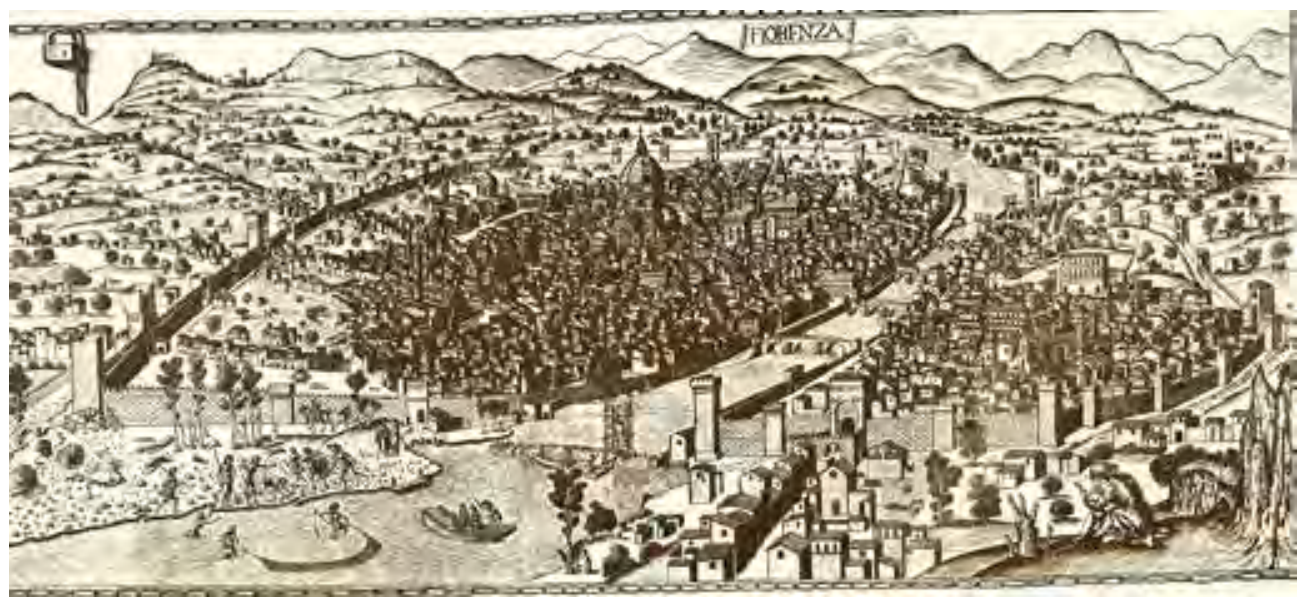

Plano y vista de Florencia. Siglo $X$

Fuente: http://culturamegellana.com/2014/01/18/il-concetto-di-historia-una-lunga-catena-le-cuimagliesono-strette-luna-allaltra/ 
La idea de ciudad en el quattrocento pasa, efectivamente, por la intención de racionalizar u ordenar una ciudad, que producto de espontáneos crecimientos se erigía como un enmarañado de calles y edificaciones. De estos "ordenamientos" quedan muchos en la teoría y en contadas realizaciones, como la organización que a partir de la arquitectura del Ospedale degli Innoncenti, propone Brunelleschi para la Piazza della S.S. Anunziatta, en la propia Florencia; o la sistematización de Roma por parte de Sixto V, a través del tridente que con- verge en la Piazza del Popolo. Sin embargo, es difícil creer que los tratadistas renacentistas hayan influido en nuestros aventureros conquistadores. Es difícil creer que personajes, en su mayor parte analfabetos, hubieran podido leer a Filarete o a Alberti, que por entonces solo publicaba en latín, aumentando su dificultad de difusión; o que estuvieran inspirados en la célebre Amaurout de la Utopía de Tomás Moro o la Ciudad del Sol de Campanella, textos cuyas versiones castellanas son con seguridad del siglo XVII en adelante.

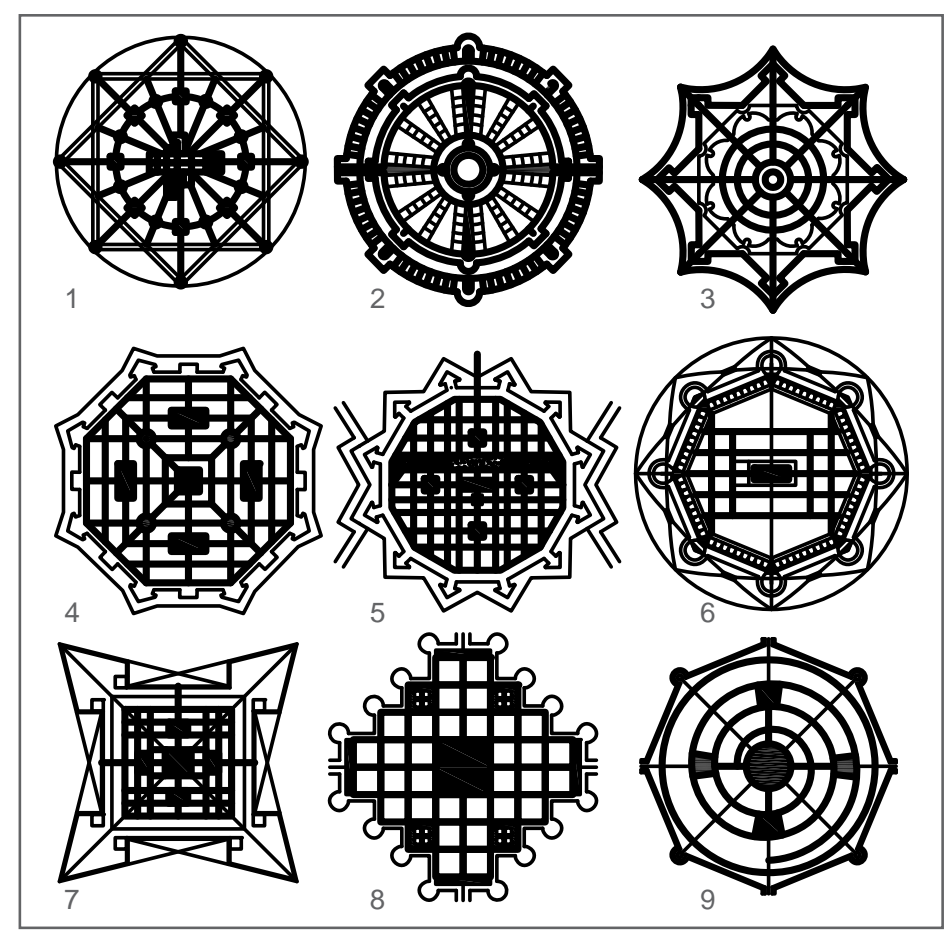

Diferentes concepciones renacentistas de la ciudad ideal: 1. La Sforzinda, por Filarete (1460-1465); 2. Fra Giocondo (Giovanni de Verona), c. 1433-1515; 3. Girolamo Magi (o Maggi) (c. 1523 - c. 1572) (1564); 4. Giorgio Vasari (1598); 5. Antonio Lupicini (c. 1530 - c. 1598); 6. Daniele Barbaro (1513-1570); 7. Pietro Cattaneo (1537-1587); 8/9; Francesco di Giorgio Martini (1439-1502).

Fuente: http://es.slideshare.net/fcoabarca/las-ciudades-del-renacimiento-y-barroco-la-magnitud-eje-de-plano 
Por eso, el trazado fundacional de las ciudades americanas es una creación absoluta de este continente, hecha por europeos sobre un territorio nuevo, que respondió a objetivos pragmáticos de tipo militar y religioso evangelizador, que se fue enriqueciendo en el proceso hasta derivar en las famosas Leyes de Indias, que servirían para el trazo de nuevas ciudades en el siglo XVII'. Por lo tanto, se convierte en el primer aporte americano a la urbanística mundial. Coinciden, sin saberlo, en su pragmatismo con las ciudades romanas, y con la intención de orden que trae toda la humanística renacentista, que probablemente sea un sentimiento de la época más que una teoría aplicada.

\section{Francisco Pizarro, urbanista}

Dentro de ese aspecto es que también debe entenderse la figura histórica de Francisco Pizarro, conquistador del Perú y fundador de Lima. La acuciosa biografía escrita por el doctor José Antonio del Busto (2001), nos devela varios aspectos desconocidos de su vida, entre los que me permitiré destacar los referidos al urbanismo.
Pizarro participa desde muy temprano en la gesta de la invención de América. Las primeras referencias de su presencia en el nuevo continente lo sitúan en la isla La Española, a donde arriba en 1502, procedente de España. En ese mismo año Cristóbal Colón realiza su cuarto y último viaje, durante el cual navegará la costa de la actual Honduras, en busca del paso al océano Índico².

En La Española (hoy República Dominicana), y estando al servicio del gobernador, don Nicolás de Ovando, probablemente participa, entre 1503 y 1506, en la fundación de diferentes ciudades, entre ellas Puerto Plata, Santa María de la Vera Paz, Lares de Guaba, San Juan de la Maguana, Buenaventura, Villanueva de Yáquimo, Compostela de Azúa, Santa Cruz, Salvaleón, Salvatierra de la Savana, Bonao, Concepción, Árbol Gordo y el traslado de Santo Domingo a la orilla izquierda del río Ozama (1504). Del Busto apunta que esta experiencia es importante, por cuanto a la llegada de Ovando a La Española encontró solo cuatro ciudades: La Isabela, Concepción de la Vega, Santiago y la capital, Santo Domingo, pero entendió que para la to-

1 Leonardo Mattos (1989) señala que luego de su promulgación en 1573, por Felipe II, las ordenanzas de "Nuevos descubrimientos y poblaciones" llegaron al Perú, y en general a América, cuando la mayoría de las poblaciones estaban ya establecidas.

2 Parto de la premisa aceptada de que Cristóbal Colón murió sin aceptar que el continente que había descubierto era uno distinto del Asia. Al respecto, sugiero leer el libro La invención de América de Edmundo O'Gorman (2003). 
tal sojuzgación de la isla era necesario fundar más. Luego anota "Francisco Pizarro, concurrente a más de una de estas nuevas creaciones, debió beber el plan ovandino de su futura actitud fundacional" (Del Busto, 2001, p. 70).

Su experiencia en el gobierno edilicio la inicia en Panamá, en 1519, donde es nombrado por el gobernador Pedrarias Dávila como regidor, en agradecimiento a los servicios prestados como soldado en la gesta contra Vasco Núñez de Balboa. Posteriormente fue alcalde de la misma ciudad. Su práctica urbanística continuó cuando acompaña al propio gobernador Pedrarias a la fundación de la Villa de Santiago de los Caballeros de Natá, el 20 de mayo de 1522, donde eligen cabildo y reparten los solares (Del Busto, 2001, pp. 105-106).

Pizarro fundó en el Perú la ciudad de San Miguel de Tangarará (Piura), el 15 de agosto de 1532. Posteriormente, y ante la amenaza de Pedro de Alvarado, gobernador de Guatemala, de invadir por mar en reclamo de estas tierras ${ }^{3}$, fundó las ciudades del Cusco (23 de marzo de 1534) y Jauja (25 de abril de 1534) ${ }^{4}$. Controlada la amenaza de Alvarado por los buenos oficios de
Almagro, se abocó Pizarro a ocupar la costa y fundar una ciudad a la que pudiera trasladar la capital del Perú, la Ciudad de los Reyes (Lima), el 18 de enero de 1535. Posteriormente fundó Trujillo (5 de marzo de 1535), y luego de la guerra con Manco Inca y buscando un punto intermedio entre Lima y Cusco, la ciudad de San Juan de la Frontera de Huamanga (Ayacucho).

Aunque no participó directamente en su fundación, lo hizo de manera indirecta con las ciudades de Chachapoyas, Moyobamba, Huánuco y Arequipa. Asimismo, envió instrucciones para la fundación de la Ciudad de la Plata, en Charcas, actual Sucre, en Bolivia.

Sin embargo, es importante señalar que su labor no se limitó al acto fundacional, sino que participaba activamente en el trazado e incluso en la edificación de los primeros solares. En el caso de la fundación de Jauja, dice Del Busto:

el gobernador Pizarro, ayudado por Juan de Pancorbo, midió el terreno destinado al templo. Luego procedió al reparto de los solares, señalándose uno para el convento de los dominicos. En los días sucesivos los indios curacas huancas Cusichaca y Hua-

3 El gobernador Pizarro - que por ser hombre viejo conocía la forma de frenar intrusos- se apresuró a fundar el Cusco, evitando de este modo que Alvarado hallase la tierra sin fundaciones españolas y se pudiese aferrar a ese pretexto (Del Busto, 2001, p. 237).

4 La intención de fundar Jauja estuvo manifiesta desde la llegada de Pizarro, en octubre de 1532, al valle de Jauja, más tarde llamado valle del Mantaro, debido a la belleza del lugar y a la hospitalidad de los huancas, que vieron en los españoles a los libertadores del yugo de los incas (Del Busto, 2001, pp. 207-213). 
cra Paucar, empezaron a edificar la ciudad (2001, p. 242).

\section{La fundación de Lima}

La fundación de Lima debe ser vista como un proceso que empezó con la selección correcta del lugar. Para tal efecto, Pizarro, que por entonces había bajado de Jauja a Pachacamac, ordenó a tres de sus jinetes: Ruy Díaz, Juan Tello de Guzmán y Alonso Martín de Don Benito, la búsqueda de un paraje donde fundar una nueva ciudad, que sería la capital del Perú.

La expedición partió de Pachacamac el 6 de enero de 1535, Día de los Reyes Magos, y para el día 13 de enero informaron a Pizarro de la ubicación de un paraje dentro de un extenso valle, que lo regaba un río al que los indios llamaban Rímac, que quiere decir el Hablador. El valle se veía propicio para la fundación de una ciudad porque "tenía buen clima, mucha agua y leña, tierra para sementeras y cerca había un puerto natural propicio para el surgir de las naves" (Del Busto, 2001, p. 250).

Satisfecho con el informe de la expedición, Pizarro decidió fundar la ciudad que llamó de los Reyes, como advocación a los Reyes Magos, en cuya fecha había partido la expedición para la selección del sitio. Nótese cómo el conquistador sitúa el acto fundacional en el inicio de la empresa y lo concluye con el acto de fundación en sí mismo, el 18 de enero de 1535.
Al igual que en la fundación de Cusco y Jauja, el acto de fundación de Lima se hizo al centro de un cuadrado que pasó a ser después la Plaza Mayor. Al centro de este cuadrado se ubicó una picota o rollo, especie de tronco tajado en punta en la parte superior que se plantaba desde la víspera y que significaba la justicia real. Es en este tronco (picota) donde se hacía el acto de fundación de la que participaban los futuros vecinos, que portando sus mejores armas se aproximaban haciendo un ruedo en torno a la picota. Es importante resaltar el carácter militar del acto de fundación, tal como lo señala Del Busto:

Entonces, aquietados y en silencio, el capitán desenvainaba la espada y proclamaba a los cuatro vientos su intención de fundar allí una ciudad, añadiendo que lo hacía para mayor servicio de Dios y el Rey. También voceaba el nombre de la nueva urbe y desafiaba a los que asistían al acto a batirse y dirimir por las armas toda disconformidad sobre la elección del sitio... conseguida la uniformidad de criterio, se acercaba el fundador al rollo y, levantando la espada, lo hería de arriba abajo descortezándolo en parte (2001, p. 254).

Una vez acabado el rito fundacional, Pizarro mismo trazó los solares. El primer solar fue para la iglesia, donde hoy está la Catedral, dedicada a la Virgen de la Asunción, puso la primera piedra y los primeros maderos de ella. Acto seguido repartió los solares de la ciudad a los futuros ha- 
bitantes. En la plaza fundacional se ubicaron, además de la iglesia, el solar del gobernador y el cabildo, quedando así ubicadas las tres instituciones de lo que Porras Barrenechea llama "el drama español del siglo XVI": Dios, el Rey y el Pueblo (Porras, 2002, p. 8).

Sin embargo, es importante enfatizar que las intenciones para la nueva ciudad fundada eran de las mayores. El cronista Pedro Cieza de León señala que la voluntad de esta fundación respondía a grandes propósitos. Mientras Juan Tello repartía los solares: “dizen que dezia... quando entendía en esto que avia de ser aquesta terra otra Italia, y en el trato segunda Venecia, porque tanta multitud de oro y plata avia hera imposible que no fuese asi" (Cieza de León, 1995, p. 267) ${ }^{5}$.

Por otro lado, hay ciertos aspectos, que recoge el acta de fundación, que es necesario resaltar, pues tienen que ver con la concepción religiosa de ciudad que Pizarro formula. En el acta levantada por don Domingo de la Presa, se señala expresamente que esta ciudad:

Repartió los solares a los vecinos del dicho pueblo segund parescera por la traca que de la dicha cibdad se hizo la qual espera en nuestro Señor y en su bendita madre que sera tan grande y tan prospera quanto conviene y la conservara e augmentara perpetuamente de su mano pues es fecha e edificada para su sancto servicio y para que nuestra santa fee catholica sea ensalzada abmentada e comunicada e sembrada entre estas gentes barvaras que hasta agora an estado desbiadas de su conoscimyento e verdadera dotrina e servicio para que la guarde e Conserve e libre de los peligros de sus enemigos e de los que mal e daño le quisiesen hacer ${ }^{6}$.

La visión que Pizarro plantea para esta nueva ciudad corresponde correctamente a lo expresado por la escolástica agustiniana. En el libro Ciudad de Dios, San Agustín dice, referido a los fines, lo siguiente:

Nos dio además todo lo necesario para conservar o recobrar esta paz; así como lo propio y conveniente al sentido, la luz, la noche, las auras respirables, las aguas potables y cuanto sirve para alimentar, cubrir, curar y adornar el cuerpo. Todo esto nos lo dio bajo una condición, muy justa por cierto: que el mortal que usara rectamente de tales bienes los recibirá mayores y mejores. Recibirá una paz inmortal acompañada de gloria y el honor propio de la vida eterna, para gozar de Dios y del prójimo en Dios. Y el que los usara mal no recibirá aquéllos y perderá éstos (Agustín, 1941, Libro 20, capítulo XIII).

5 Esto también es citado por Leonardo Mattos (1989, p. 74). Al respecto es importante señalar que Pizarro antes de venir a América, había servido como soldado en Italia entre 1495 y 1498 , habiendo participado en la batalla de Murano, isla vecina a Venecia (Del Busto, 2001, p. 509).

6 http://limavirreynal.blogspot.com/2007/02/del-acta-de-fundacion-de-lima.html 
Sin embargo, creo que este no fue el único propósito religioso de la empresa. Aparte de los objetivos militares o pragmáticos, postularé la hipótesis de la fundación como un acto de evangelización en sí mismo. Creo que el hecho de escoger un paraje cercano a Pachacamac dice mucho de la necesidad de yuxtaponer una religión a otra, empezando un proceso de sincretismo, que en la práctica se dio.

La voluntad de fundar una ciudad en la costa tenía un objetivo militar y geopolítico. La idea de hacerlo cerca de Pachacamac, un objetivo religioso. La fundamentación de esto la podemos encontrar en el descarte que hace Pizarro de otras dos ciudades. La primera de ellas es San Gallán, a orillas del río Pisco y cerca de la actual ciudad del mismo nombre, donde ya se había asentado un grupo de españoles, que después serían llamados a poblar Lima. Ubicar una ciudad más al sur, hubiera sido muy conveniente para el conquistador que por entonces reclamaba a la corona ampliar sus dominios hacia el sur. La otra ciudad que a juicio de Almagro debería ser la capital fue lo que después se llamó Trujillo del Perú, en lo que llamaban el valle del Chimo. Para tal efecto, Almagro, a su regreso de Quito, pasó por el lugar y dejó un pequeño contingente a cargo de Martín de Estete, en espera de retornar con Pizarro para la fundación respectiva. Cosa que sucedió, pero con posterioridad a la fundación de Lima, que ya había sido designada como capital. Se descartó esta segunda ciudad, tal vez por estar más al norte.

\section{El diseño de la ciudad}

Desde el punto de vista de su diseño o trazado, en el caso de la fundación de Lima la habilidad urbanística de Pizarro fue más importante en relación a otras fundaciones. Empezó por la selección del lugar, como lo manifiesta el cronista Pedro Cieza de León, que arriba al Perú en 1547 con el pacificador Pedro de la Gasca:

La ciudad está asentada de tal manera, que nunca el sol toma al río de traués, sino que nasce a la parte de la ciudad. La cual está tan junto al río, que desde la plaça vn buen braçero puede dar con vna pequeña piedra en él (1995, p. 212).

Por otro lado, a diferencia del Cusco o Jauja, que se fundan sobre asentamientos existentes, el caso de Lima fue casi una verdadera implantación, ya que se hizo sobre un pequeño y poco significativo asentamiento prehispánico, tal como lo establece el cronista Bernabé Cobo:

Que asentada la ciudad, conforme a la planta y dibujo que para ello se hizo en papel, en el mismo asiento del pueblo de indios dichos Lima, que estaba a la banda del río, a la banda del sur, que hoy ocupa la plaza y casas reales (2002, p. 33). 
O en un páramo, como lo establece Cieza de León, que dice lo siguiente: "Y luego se hizo la traça y se edificó la ciudad, en un pequeño campo razo de este valle" (1995, p. 211).

Sobre el trazado de la ciudad, dice Porras Barrenechea:

fue seccionada como un tablero de ajedrez en 117 islas o cuadras. Cada manzana de 15,687 metros fue dividida en cuatro solares. Las calles anchas y derechas orientadas del sudeste al noroeste, consultaban a toda hora del día hubiese una acera en la sombra, al mismo tiempo que los vientos alisios, que soplan constantemente del lado Sur, incidiesen de un lado oblicuo para la correcta circulación del aire (2002, p. 8).

La forma urbana deriva, en principio, de la traza en forma de damero o cuadrícula. Como elemento central y característico de todas las ciudades hispanoamericanas se situó la Plaza Mayor. Las irregularidades que luego cambian el trazado original y que pueden observarse en el plano de reconstrucción de Bromley y Barbagelata se deben a la existencia de caminos incas, uno de ellos muy importante emplazado en diagonal de norte a sur y otro en el actual eje Quilca-Miró Quesada, interrumpido por la tra-

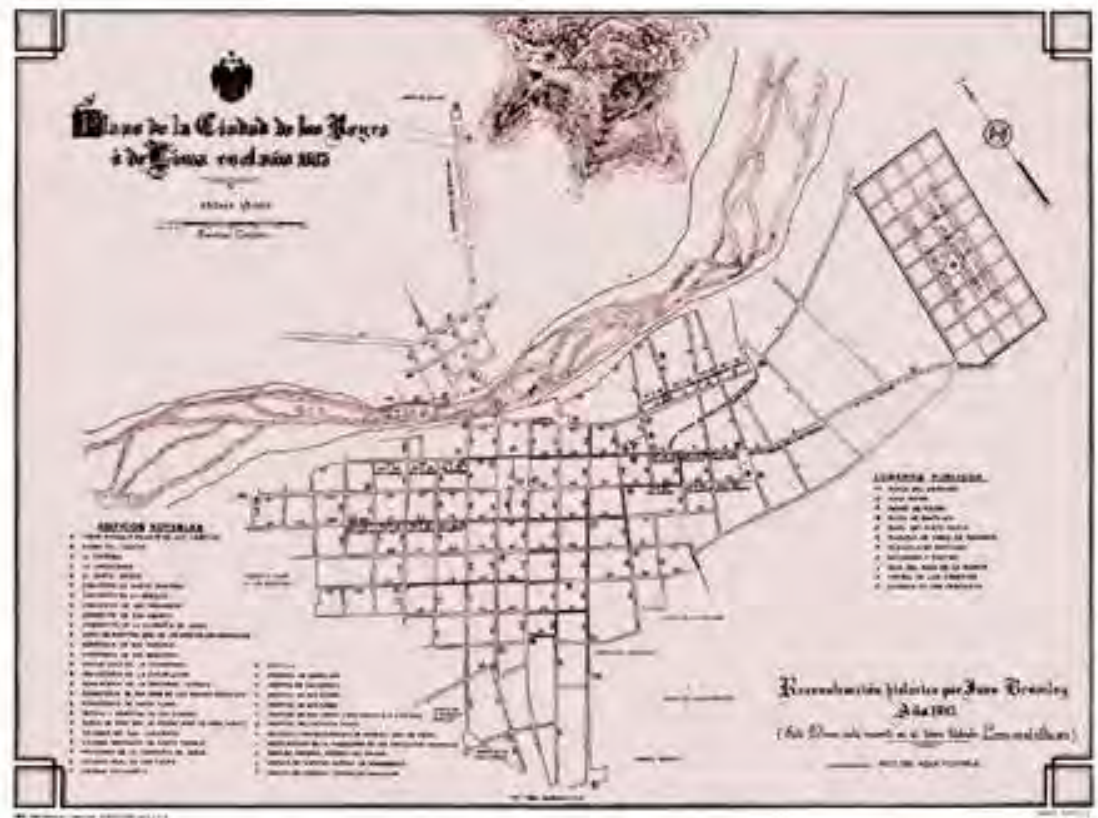

Plano de la Ciudad de los Reyes, 1613; reconstrucción histórica de Juan Bromley y José Barbagelata.

Fuente: Belaunde Terry, 1945.

Elaboración propia. 


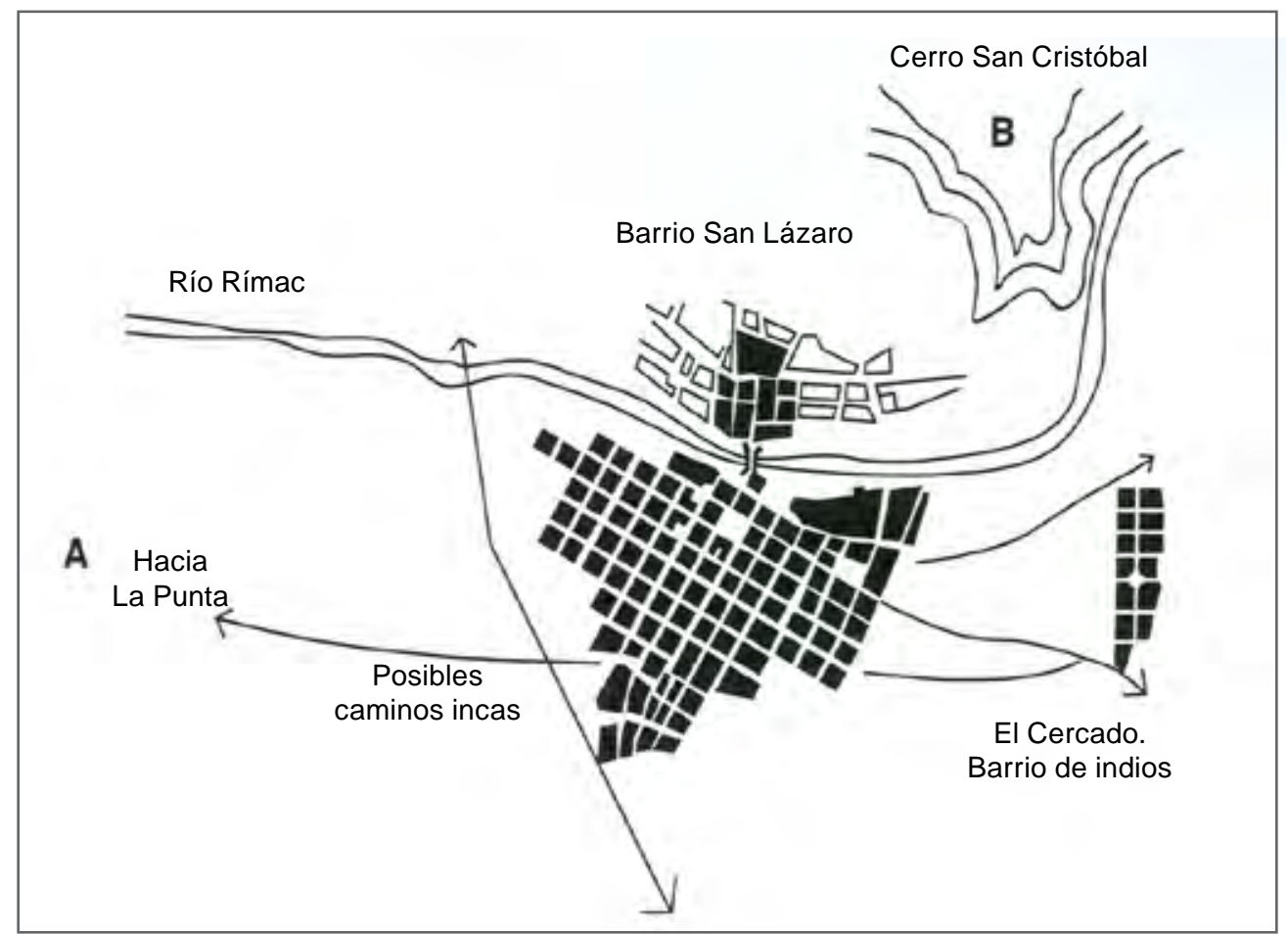

Interpretación del plano.

Elaboración propia.

ma urbana del damero a la altura de la Plaza San Martín. Además de los caminos, es importante también la presencia de los canales o acequias de regadío, que alteran la trama de la ciudad, como por ejemplo el trayecto del río Huatica en Barrios Altos. Posteriormente, las alteraciones de la trama se debieron a la existencia de la muralla, que se constituyó en un límite obligado de la ciudad.

Lo cierto es que la empresa urbanística fue majestuosa, tal como la describe el propio Cieza:
Esta ciudad después del Cuzco es la mayor de todo el reyno del Perú, y la mas principal: y en ella ay muy buenas casas y algunas muy galanas con sus torres y terrados, y la plaça es grande y las calles anchas. Y por todas las mas de las casas passan acequias, que es no poco contento: del agua de ellas se sirven y riegan sus huertas y jardines que son muchos frescos y deleitosos (Cieza de León, 1995, p. 212).

La ciudad de Lima fue, sin lugar a dudas, la obra máxima de Pizarro y la culminación de su práctica urbanística. 
Porras Barrenechea dirá que la fundación de Lima, "fue obra del azar, sino de la equivocación y su prosperidad, producto de la buena fortuna de su fundador". En otra parte mencionará:

sin ofender los títulos que después adquirió y sin hacer agravio a su tradición ya venerable debe decirse que la capital fundada por Pizarro fue en aquellos días del apogeo del Cuzco, de Cajamarca y de Quito, una ciudad advenediza, la hija y la heredera de aquel audaz aventurero (2002, pp. 6 y 7).

\section{Epílogo}

La ciudad hispanoamericana del siglo XVI significó para la corona un punto de avanzada militar que indicaba la posesión de la tierra y un punto de irradiación cultural y religiosa. Hasta allí los objetivos, es decir la teoría de la fundación. Sobre el modo de hacerlo no había sino el pragmatismo del soldado, como Pizarro, que a fuerza de ir fundando ciudades iba enriqueciendo su capacidad urbanística. Praxis que llegará a su expresión más alta en la fundación de Lima, cuyo ejemplo se irradiará a las otras fundaciones de ciudades en las posesiones españolas en Sudamérica e inclusive Filipinas.

A partir de la tesis de Edmundo O'Gorman (2003) de que América no fue descubierta, sino inventada, se puede postular que la ciudad hispanoamericana es también un invento, que sirvió en principio con propósitos militares, de ocupar territorio.
Su traza respondió inicialmente a un modelo pragmático, derivado de los campamentos militares y se fue enriqueciendo a medida que se iban instalando las órdenes religiosas y algunos servicios. Por lo tanto, la ciudad renacentista, alentada por las intenciones europeas de orden y geometría, es un producto absolutamente americano y la primera contribución de nuestro continente a la historia de la urbanística occidental.

Por lo tanto, Lima es una ciudad renacentista, no solo por el tiempo de su fundación, que coincide con el cinquecento italiano, sino que además encarna la voluntad y tal vez el sueño de orden que Europa desea para superar el caos de la ciudad medieval.

\section{Referencias}

Agustín, S. (1941). Ciudad de Dios. Buenos Aires: Poblet.

Belaunde Terry, F. (1945). Evolución urbana de Lima: una obra de Juan Bromley y José Barbagelata. El Arquitecto Peruano. Lima.

Cieza de León, P. (1995). Crónica del Perú (Vol. 1). Lima: Pontificia Universidad Católica del Perú, Fondo Editorial.

Cobo, B. (2002). La fundación de Lima. En R. Porras Barrenechea. Antología de Lima (Vol. 1, pp. 23-35). Lima: Fundación Bustamante de la Fuente.

De Presa, D. (16 de febrero de 2007). Historia de Lima virreynal. 
Recuperado de http://limavirreynal. blogspot.com/2007/02/del-acta-defundacion-de-lima.html

Del Busto Duthurburu, J. A. (2001). Pizarro. Lima: Ediciones Cope.

Mattos Cárdenas, L. (1989). Ciudad de Dios y ciudad hispanoamericana. Modelos occidentales del urbanismo andino del siglo XVI. En G. Massa. La mistica spagnola. Spagna America Latina (pp. 73-98). Roma: Dowling College.
O'Gorman, E. (2003). La invención de América. México: Tierra Firme.

Porras Barrenechea, R. (2002). Perspectiva y panorama de Lima. En R. Porras Barrenechea. Antología de Lima (Vol. 1, pp. 3-19). Lima: Fundación Bustamante de la Fuente.

Velarde, H. (1966). Lima la horrible. En H. Velarde. Obras Completas (pp. 257-259). Lima: Francisco Moncloa Editores. 